\title{
A case report of complex auricular neuralgia treated with the great auricular nerve and facet blocks
}

This article was published in the following Dove Press journal: Journal of Pain Research

17 February 2017

Number of times this article has been viewed

\author{
Marzieh Eghtesadi' \\ Elizabeth Leroux ${ }^{2}$ \\ Grisell Vargas-Schaffer ${ }^{3}$ \\ 'Department of Pain Clinic, Headache \\ Management, Centre Hospitalier de \\ I'Université de Montréal (CHUM), Centre \\ de Recherche de l'Université de Montréal \\ (CRCHUM), ${ }^{2}$ Department of General \\ Neurology, Headache Management, \\ Centre Hospitalier de l'Université de \\ Montréal (CHUM), Centre de Recherche \\ de l'Université de Montréal (CRCHUM), \\ ${ }^{3}$ Department of Anesthesiology, Pain \\ Clinic, Centre Hospitalier de I'Université \\ de Montréal (CHUM), Centre de \\ Recherche de l'Université de Montréal \\ (CRCHUM), Montreal, QC, Canada
}

Video abstract

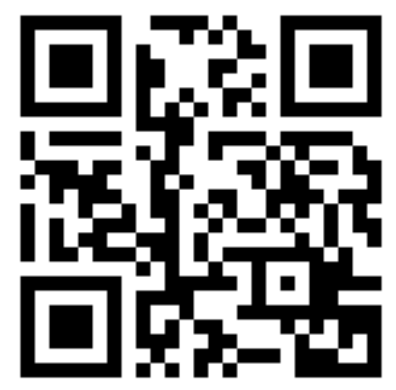

Point your SmartPhone at the code above. If you have a QR code reader the video abstract will appear. Or use: http://youtu.be/bccCtE3DBxE

Correspondence: Marzieh Eghtesadi Department of Pain Clinic, Headache Management, Centre Hospitalier de I'Université de Montréal (CHUM), 3840 rue Saint Urbain, Hôpital Hôtel-Dieu du CHUM, Clinique antidouleur 2 étage, Pavillon Jean

Mance, Montreal, QC H2W IT8, Canada

Tel + I 5148908000

Fax + I 514412 7I32

Email marzieh.eghtesadi@mail.mcgill.ca
Background: The great auricular nerve is a cutaneous branch of the cervical plexus originating from the $\mathrm{C} 2$ and $\mathrm{C} 3$ spinal nerves. It innervates the skin over the external ear, the angle of the mandible and the parotid gland. It communicates with the ansa cervicalis. Great auricular neuralgia is rarely diagnosed in clinical practice and can be refractory. We present a new approach using ultrasound-guided nerve blocks.

Case: We present a case of a 41-year-old female with paroxysmal ear pain accompanied by dysautonomia, tingling in the tongue, dysphagia, dysarthria and abdominal symptoms. No significant findings were found on cervical and brain imaging. The patient responded partially to a great auricular nerve block. A combined approach using this block with facet block of C2 and $\mathrm{C} 3$ induced a more pronounced and prolonged benefit.

Conclusion: Great auricular neuralgia is not often encountered in practice and can be accompanied by symptoms originating from the ansa cervicalis network. A combined approach of nerve blocks can be considered in refractory cases.

Keywords: ansa cervicalis, neuropathic pain, facet block, red ear syndrome, great auricular nerve

\section{Introduction}

The great auricular nerve (GAN) is a cutaneous branch of the cervical plexus originating from the $\mathrm{C} 2$ and $\mathrm{C} 3$ spinal nerves. ${ }^{1}$ It innervates the skin over the external ear, the angle of the mandible and the parotid gland. ${ }^{2}$ Here, we present a case of unusual ear pain with dysautonomia and gastrointestinal manifestations. The patient was refractory to usual neuropathic pain pharmacotherapy.

Great auricular neuralgia is a rare condition. It can be associated with symptoms linked to the cervical plexus. Treatment may include a combination of peripheral nerve blocks targeting the GAN itself and the $\mathrm{C} 2-\mathrm{C} 3$ cervical roots.

\section{Case presentation}

The patient is a 41-year-old female who presented with a 1-year history of paroxysmal left ear pain and tingling sensation in her tongue. The pain in her ear radiated to the ipsilateral side of her face as well as posteriorly in the distribution of the lesser occipital nerve. She reported associated jaw clenching and allodynia to teeth brushing and mastication. The pain worsened at the end of the day to a severe intensity, at which time there was red discoloration of the ear. The patient alternated between a constant dull aching pain at 5 out of 10 and periods of paroxysmal pain reaching 8 out of 10 on a numerical rating scale and lasting between 1 and 5 consecutive days. 
During exacerbations, the patient also complained of dysphagia and dysarthria. Other symptoms included postprandial abdominal pain and diarrhea.

There was a history of sports-related mild traumatic head injury as a young adult and a whiplash involving subluxation of the C4-C5 cervical vertebrae. Past medical history also included mononucleosis, two previous superficial lower extremity venous thromboses postpartum and heterozygous factor V Leiden thrombophilia.

Examination of her cranial nerves revealed diffuse hypoesthesia to touch, pinprick and temperature in the left trigeminal distribution. No intraoral trigger points were identified. There was decreased sensation to touch and pinprick in the area of the greater and lesser occipital nerves. The gag reflex on the left side was absent. Lateral neck flexion to the right was limited with diffuse tenderness on palpation of the left paracervical muscles. Neck compression testing for radiculopathy and facet syndrome using Spurling's maneuver was able to provoke the patient's red ear discoloration after a 15 -second compression.

The patient's workup included a $3 \mathrm{~T}$ cerebral angiomagnetic resonance imaging with contrast, Constructive Interference in Steady State sequence imaging of the circle of Willis and magnetic resonance imaging of the cervical spine. A contact between the superior cerebellar artery and the cisternal portion of the left trigeminal nerve was seen, but without evidence of compression. A chest X-ray was normal. Rheumatological workup showed mildly elevated antinuclear antibodies, but was otherwise inconclusive for collagenosis. Gastrointestinal workup, including food allergy testing, gastroscopy and colonoscopy with biopsies were negative.

Drug trials included acetaminophen, naproxen, tricyclic antidepressant, gabapentinoids, carbamazepine, topical analgesics, bupropion, muscle relaxant, tapentadol, morphine, hydromorphone and methadone. Pharmacotherapy was unsuccessful in this patient. In addition, she developed a multiple drug intolerance syndrome, including a probable Stevens-Johnson with carbamazepine.

She was evaluated by an allergist. Due to the serious nature of side effects, all pain medications had been stopped at least 2 weeks prior to the ultrasound-guided infiltrations described below.

A diet at the patient's own initiative proved slightly successful in reducing her postprandial abdominal pains.

The patient was initially diagnosed with trigeminal neuralgia. The diagnosis was later revised to great auricular neuralgia, given the distribution of the pain. Additional symptoms were attributed to a dysfunction at the level of the ansa cervicalis.

We initially performed a GAN block using ultrasound guidance (Figure 1). We used a GE Logiq $\mathrm{e}^{\circledR}$ Ultrasound machine equipped with a $12 \mathrm{MHz}$ high-frequency transducer. The GAN was identified at its emergence from the posterior border of the sternocleidomastoid muscle, at the level of the cricoid cartilage located by palpation. ${ }^{3,4}$ Once the hypoechoic round shaped nerve was visualized, a $25 \mathrm{G}, 50 \mathrm{~mm}$ needle was introduced in plane with the ultrasound probe, and we injected a mix of $1 \mathrm{~mL} 2 \%$ xylocaine, $1 \mathrm{~mL} 0.5 \%$ bupivacaine and $1 \mathrm{~mL}$ of triamcinolone $(40 \mathrm{mg})$. This technique proved successful in relieving the patient's paroxysmal earaches for over 1 month with reduction of pain intensity of $60 \%$. The patient reported improvement within 48 hours following nerve block of the GAN. No adverse events were reported.

Three months later, the patient's pain was back at baseline. We combined the GAN block with ultrasound-guided facet blocks of the $\mathrm{C} 2$ and $\mathrm{C} 3$ spinal nerves as well as lesser occipital nerve block. We injected $2 \mathrm{~mL}$ of the same analgesic mix at each infiltration point. The combination of these blocks reduced not only the intensity of her paroxysmal ear pain, but also the duration of exacerbations from 1 to 5 days to $<24$ hours and the background pain by $>50 \%$. The relief was more prolonged, lasting for over 2 months.

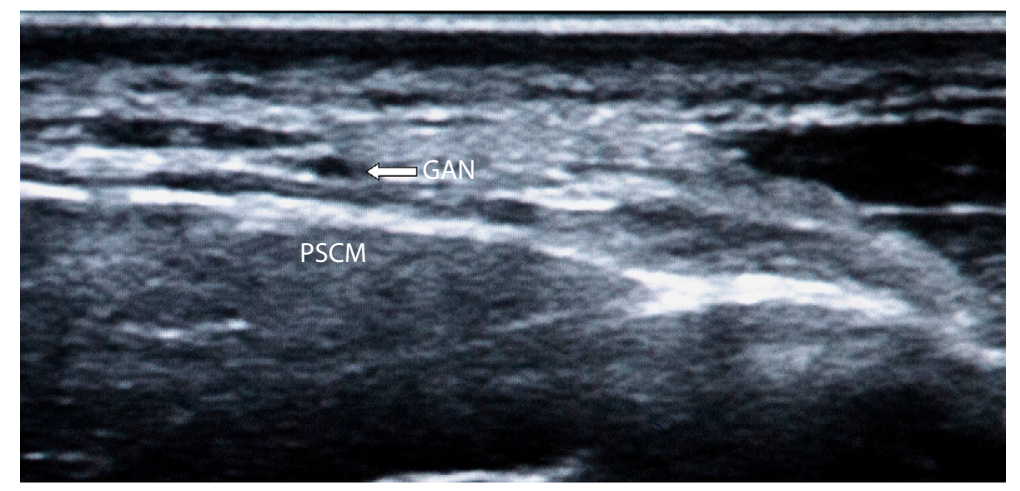

Figure I Ultrasound-guided transverse view of the GAN.

Abbreviations: GAN, great auricular nerve; PSCM, posterior border of sternocleidomastoid muscle. 


\section{Discussion}

The GAN arises from the ventral rami of $\mathrm{C} 2-\mathrm{C} 3$ roots, along with two other sensory branches, the lesser occipital nerve and the transverse cervical nerve. ${ }^{5}$ The fourth cervical cutaneous nerve and the supraclavicular nerve arise from $\mathrm{C} 3-\mathrm{C} 4{ }^{6}$

The GAN has anastomoses with the auricular branch of the vagus nerve, the posterior auricular branch of the facial nerve, the lesser occipital nerve and the auriculotemporal nerve of the trigeminal nerve.,

The ansa cervicalis, also known as goose's neck or ansa hypoglossi, is a loop of nerves formed by the ventral rami of $\mathrm{C} 1$ to $\mathrm{C} 4$ which join the hypoglossal nerve via a branch of $\mathrm{C} 1$ (Figure 2). ${ }^{59} \mathrm{It}$ is also involved in the innervation of infrahyoid muscles, which are important for speech modulation and swallowing. ${ }^{10}$

The case presented above illustrates this complex network of connections and suggests a dysfunction at a more proximal level than the peripheral branches. However, the mechanical disturbance and trigger at the neck, along with the presence of digestive symptoms prompt us to believe that the primary dysfunction is proximal to the peripheral cutaneous branches of the cervical plexus, most likely within the ansa cervicalis. ${ }^{5,9,10}$

However, a central dysregulation of the brainstem trigeminal-autonomic circuits cannot be ruled out.

Contrary to cases of red ear syndrome described in the literature, this patient did not have another primary headache disorder, such as migraine. ${ }^{11}$ History and physical examination revealed pain of neuropathic origin as per the Douleur Neuropathique 4 questionnaire, but the patient suffered serious adverse reactions to usual neuropathic pharmacotherapy.

Our nerve blocks targeted the GAN peripherally in addition to its spinal nerve root origins at $\mathrm{C} 2$ and $\mathrm{C} 3$. The combination of these blocks provided more relief to the patient in terms of intensity, duration and frequency of paroxysmal earaches as well as her constant dull background pain, in comparison to blocking the GAN peripherally alone. The improvement was noticeable up to 3 months after the infiltrations. More long-term outcome is not yet known. Advantages to this technique versus fluoroscopic guidance included radiation-free imaging in a young female patient and ability to identify blood vessels in needle trajectory of a highly vascularized region, all in real time. ${ }^{12}$ Adverse events were not reported, but rare and serious complications could include injury to the vertebral artery, spinal radicular arteries, nerve roots and spinal cord direct or indirect trauma with leakage of anesthetic into the spinal canal causing motor and sensory blockade. ${ }^{13,14}$ Minor potential events could include local hematoma, bruising, soreness, transient pain exacerbation and vasovagal reactions. ${ }^{15} \mathrm{~A}$ technique aiming for the ansa cervicalis itself could be more successful, as we suspected this was the primary structure of dysfunction that could explain our patient's constellation of symptoms. We are not aware of any such case reports and this kind of technique is not yet described. Furthermore, we were unable

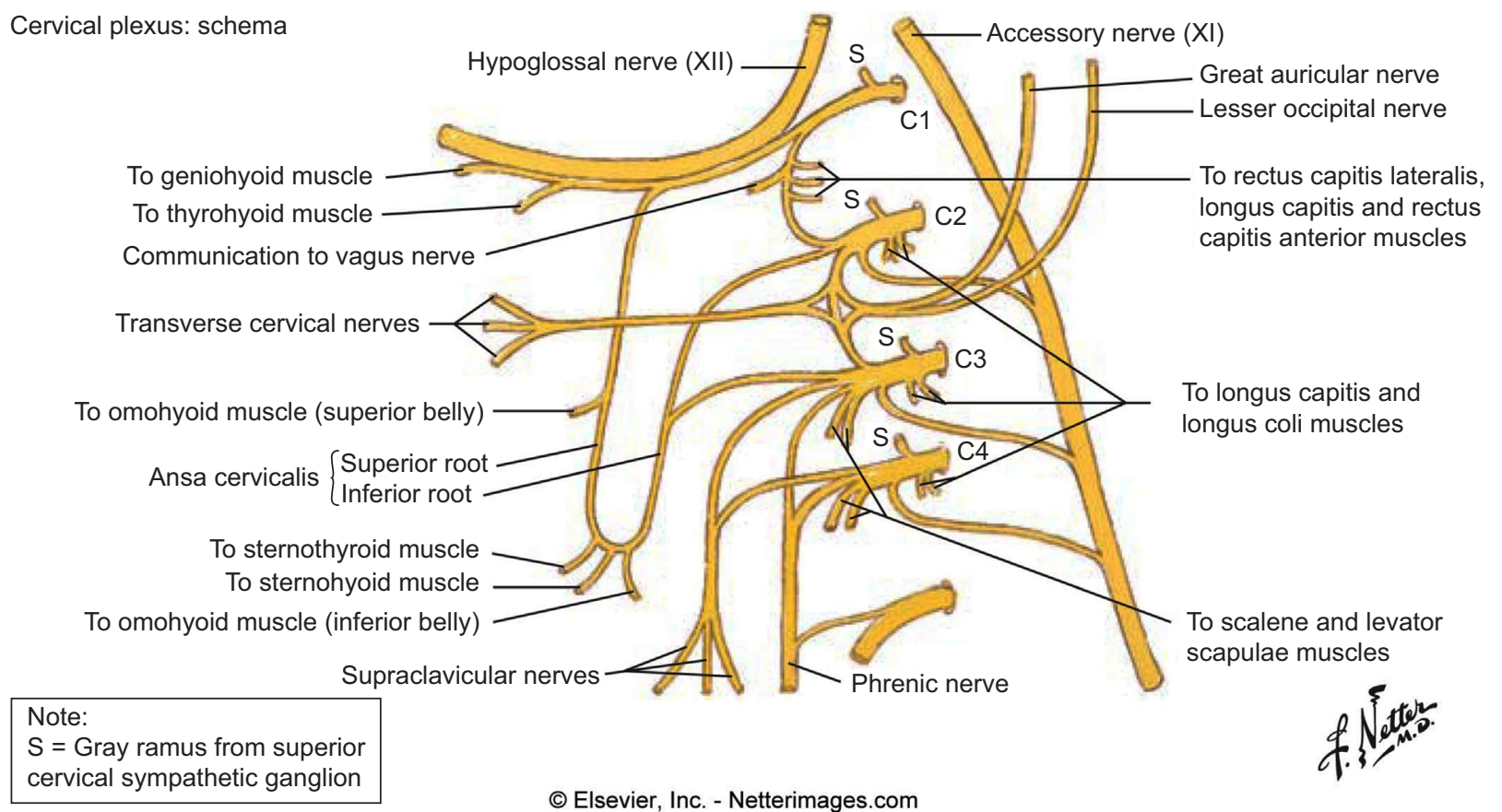

Figure 2 Cervical plexus.

Note: (c) 2014 Elsevier, Inc. All rights reserved. www.netterimages.com. Reproduced from Cochard LR, editor. Head and Neck. In: Netter's Atlas of Human Embryology. Yardley, PA: Elsevier Health Sciences; 2004: page 233. With permission of Elsevier Inc. ${ }^{17}$ 
to identify a cause or trigger to this dysfunction. However, a better understanding of the anatomical source guided our choices for better targeted nerve blocks that were able to provide our patient with symptomatic relief.

\section{Conclusion}

Great auricular neuralgia is an uncommon cause of facial pain that can be accompanied by other symptoms related to the cervical plexus. Cases refractory to usual pain medication could be treated by a combination of ultrasound-guided nerve blocks. Future potential therapeutic options would involve medial branch blocks of $\mathrm{C} 2-\mathrm{C} 3$, followed by radiofrequency ablation with or without peripheral neuromodulation of the GAN. ${ }^{16}$

\section{Acknowledgments}

The authors wish to thank Dr Werner Becker, Dr Carrie Robertson and Dr Ivan Garza for their review of this report.

Written informed consent was obtained from the patient for publication of this case report and the accompanying images.

\section{Disclosure}

The authors report no conflicts of interest in this work.

\section{References}

1. Maimone-Baronello M, Piccoli F, La Bella V. Great auricular neuralgia: a case report. Headache. 2003;43(9):1005-1006.

2. Nusair YM, Dickenson AJ. Great auricular causalgia: an unusual complication of excision of the submandibular gland. Br J Oral Maxillofac Surg. 2003;41(5):334-335.
3. Kemp WJ, Tubbs RS, Cohen-Gadol AA. The innervation of the scalp: a comprehensive review including anatomy, pathology, and neurosurgical correlates. Surg Neurol Int. 2011;2:178.

4. Thallaj A. Ultrasound guidance of uncommon nerve blocks. Saudi $J$ Anaesth. 2011;5(4):392-394.

5. Singh V. Textbook of Anatomy Head, Neck, and Brain. 2nd ed. New Delhi, India: Elsevier Health Sciences APAC; 2014.

6. Gupta C, D'souza AS, Raythe B. Anatomical variations in the emergence of the cutaneous nerves from the nerve point in the neck and identification of the landmarks to locate the nerve point with its clinical implications: a cadaveric study on south indian human foetuses. J Clin Diagn Res. 2013;7(3):413-417.

7. Elahi F, Reddy C. Neuromodulation of the great auricular nerve for persistent post-traumatic headache. Pain Physician. 2014;17(4):E531-E536.

8. Toure G. Intraparotid location of the great auricular nerve: a new anatomical basis for gustatory sweating syndrome. Plast Reconstr Surg. 2015;136(5):1069-1081.

9. Quadros LS, Prasanna LC, D'souza AS, Singh A, Kalthur SG. Unilateral anatomical variation of the ansa cervicalis. Australas Med J. 2015;8(5): 170-173.

10. Massey BT. Physiology of oral cavity, pharynx and upper esophageal sphincter. GI Motility online. Epub 2006 May 16.

11. Raieli V, Compagno A, D’Amelio M. Red ear syndrome. Curr Pain Headache Rep. 2016;20(3):19.

12. Moon JY, Chul LS. US-guided interventions cervical spine injections. Austin J Anesthesia and Analgesia. 2014;2(2):1014.

13. Hurdle M-FB. Ultrasound-guided spinal procedures for pain: a review. Phys Med Rehabil Clin. 2016;27(3):673-686.

14. Peh W. Image-guided facet joint injection. Biomed Imaging Interv J. 2011;7(1):e4.

15. Manchikanti L, Malla Y, Wargo BW, Cash KA, Pampati V, Fellows B. Complications of fluoroscopically directed facet joint nerve blocks: a prospective evaluation of 7,500 episodes with 43,000 nerve blocks. Pain physician. 2012;15(2):E143-E150.

16. Elahi F, Reddy C, Bellinger A, Manolitsis N. Neuromodulation of the great auricular nerve: a case report. Neuromodulation. 2014;17(8): 784-787.

17. Cochard LR, editor. Head and Neck. In: Netter's Atlas of Human Embryology. Yardley, PA: Elsevier Health Sciences; 2004: page 233.
Journal of Pain Research

\section{Publish your work in this journal}

The Journal of Pain Research is an international, peer reviewed, open access, online journal that welcomes laboratory and clinical findings in the fields of pain research and the prevention and management of pain. Original research, reviews, symposium reports, hypothesis formation and commentaries are all considered for publication.

\section{Dovepress}

The manuscript management system is completely online and includes a very quick and fair peer-review system, which is all easy to use. Visit http://www.dovepress.com/testimonials.php to read real quotes from published authors. 